\title{
Impulsivity and Aggression in Female BPD and ADHD Patients: Association with ACC Glutamate and GABA Concentrations
}

\author{
Gabriele Ende*, 1,4, Sylvia Cackowski',4, Julia Van Eijk', Markus Sack', Traute Demirakca', \\ Nikolaus Kleindienst ${ }^{2}$, Martin Bohus ${ }^{2}$, Esther Sobanski ${ }^{3}$, Annegret Krause-Utz ${ }^{2}$ and Christian Schmahl ${ }^{2}$ \\ 'Department of Neuroimaging, Central Institute of Mental Health, Medical Faculty Mannheim/Heidelberg University, Mannheim, Germany; \\ ${ }^{2}$ Department of Psychosomatic Medicine and Psychotherapy, Central Institute of Mental Health, Medical Faculty Mannheim/Heidelberg University, \\ Mannheim, Germany; ${ }^{3}$ Department of Psychiatry and Psychotherapy, Central Institute of Mental Health, Medical Faculty Mannheim/Heidelberg \\ University, Mannheim, Germany
}

Borderline personality disorder (BPD) and attention-deficit-hyperactivity disorder (ADHD) are both characterized by high impulsivity and difficulties in controlling anger and aggression. In BPD, comorbid ADHD may further increase impulsivity. For both disorders, altered MR spectroscopy levels of the neurotransmitters glutamate and GABA as well as some correlations with impulsivity were previously reported. The objective of this study was to investigate the neurotransmitters glutamate and GABA in relation to impulsivity and aggression as expressed in the anterior cingulate cortex (ACC) in groups of female patients with BPD and ADHD, respectively. Associations of glutamate and GABA levels with further BPD (symptom severity) and ADHD aspects (hyperactivity and inattention) were exploratively evaluated. IH MR spectra were acquired at 3T to determine glutamate to total creatine ratios (Glu/tCr) and GABA levels from the ACC in a BPD group $(n=26)$, an ADHD group $(n=22)$, and a healthy control $(H C)$ group $(n=30)$; all participants were females. Both patient groups showed higher scores on self-reported impulsivity, anger, and aggression compared with HCs. ACC GABA levels were significantly lower in ADHD than HC. Although measures of impulsivity were positively related to glutamate and negatively to GABA, for aggression only a negative correlation with GABA could be demonstrated. These data provide human in vivo evidence for the role of $\mathrm{ACC}$ Glu/tCr and GABA in impulsivity and aggression. If distinct associations of Glu/tCr and GABA for BPD and ADHD can be confirmed in future studies, this might yield implications for more specific pharmacological treatments.

Neuropsychopharmacology (2016) 4I, 4I0-4I8; doi:I0.I038/npp.20I5.I53; published online 8 July 2015

\section{INTRODUCTION}

Impulsivity and reactive aggression are major behavioral problems and part of the psychopathology of a variety of psychiatric disorders, such as borderline personality disorder (BPD) or attention-deficit-hyperactivity disorder (ADHD). Impulsivity consists of different components including personality traits (eg, tendency to act on the spur of the moment), deficits in executive functions (eg, attention, interference inhibition, information sampling, decision making, delay of gratification), and behavioral inhibition (Sebastian et al, 2013, 2014). Aggressive behavior frequently displayed by patients with BPD (Latalova and Prasko, 2010) and ADHD (Connor et al, 2010) is usually of two different kinds: reactive (or impulsive) aggression and instrumental aggression. Impulsive aggression refers to uncontrolled outbursts of anger in reaction to goal blocking, provocation, or frustration, whereas instrumental aggression is a relatively

* Correspondence: Professor G Ende, Department of Neuroimaging, Central Institute of Mental Health, Medical Faculty Mannheim/Heidelberg University, J5, Mannheim D-68159, Germany. Tel: +49621 1703 2971; Fax: +49 621 1703 70297।; E-mail: gabi.ende@zi-mannheim.de ${ }^{4}$ All authors contributed equally to this work.

Received 23 March 20 I5; revised 29 April 20 I5; accepted I5 May 20 I5; accepted article preview online 4 June 2015 non-emotional behavior to further one's goals of power, money, or other external gains (Berkowitz, 1993).

Both high impulsivity and difficulties in controlling anger and aggression are characteristic of affective and behavioral dysregulation in BPD and may lead to severe social and interpersonal problems in patients' lives. On a neural level, these symptoms have been associated with abnormalities in fronto-limbic networks, including the anterior cingulate cortex (ACC) (Mancke et al, in press; Sacchetti and Lefler, 2014; Sebastian et al, 2014). In previous research, altered ACC structure and function have been demonstrated in BPD (Rusch et al, 2010b). On a neurochemical level, glutamate and $\gamma$-aminobutyric acid (GABA) are considered important regulatory metabolites in this network (Comai et al, 2012a, 2012b). In a previous MR spectroscopy (MRS) study, we demonstrated that glutamate concentrations in the ACC correlated with self-reported impulsivity in female BPD patients (Hoerst et al, 2010).

ADHD is another disorder marked by impulse and anger control problems, which can lead to impairments in social functioning (Sacchetti and Lefler, 2014; Wender et al, 2001). As BPD and ADHD often co-occur, this may further increase the likelihood of increased impulsivity in BPD (Davids and Gastpar, 2005; Krause-Utz et al, 2013; Philipsen et al, 2008). A recent study (Krause-Utz et al, 2013) demonstrated that 
impulsivity is closely related to stress in BPD (Cackowski et al, 2014); whereas in ADHD impulsivity is already present under non-stress conditions.

Although GABA is the major inhibitory neurotransmitter in the brain, glutamate is the major excitatory neurotransmitter. Both relate to several psychological functions. In a study of children with ADHD, lower GABA levels in a region including parts of the primary somatosensory and motor cortices have been reported (Edden et al, 2012). In healthy adolescents and adults, two recent studies showed a negative association of GABA levels in the dorsolateral prefrontal cortex with impulsivity (Boy et al, 2011; Silveri et al, 2013). Despite these studies, Hayes argues that there is still a lack of research on GABA in the general context of impulsivity (Hayes et al, 2014). In rodents, Murphy et al recently reported implications for glutamatergic and GABAergic mechanisms in the infralimbic cortex in the expression of impulsivity (Murphy et al, 2012).

So far, the evidence that both glutamate and GABA influence impulsivity and aggression is scarce. Therefore, the aim of the present study was to investigate the relation of glutamate and GABA levels in the ACC to impulsivity and aggression in female patients with BPD, female ADHD patients, and female healthy controls (HCs). First, we hypothesized that, based on previous findings in selfreported impulsivity, anger, and aggression in BPD and ADHD, we would find higher scores on impulsivity in both patient groups compared with HCs. Second, we expected higher anger and aggression ratings and higher motor impulsiveness in ADHD patients compared with BPD patients (Krause-Utz et al, 2013; Lampe et al, 2007).

Third, we set out to test the reported correlation between ACC glutamate and impulsivity (Hoerst et al, 2010) and additionally hypothesized that GABA levels would reveal an opposite pattern from glutamate levels in their relation to self-reported impulsivity scores. Fourth, we hypothesized to find similar associations for aggression, ie, a positive correlation with ACC glutamate and a negative correlation with GABA levels.

Finally, we exploratively evaluated possible associations of glutamate and GABA ACC levels with BPD and ADHD symptoms, assessing general BPD symptom severity and the other core aspects of ADHD besides impulsivity, which are hyperactivity and inattention.

\section{MATERIALS AND METHODS}

\section{Sample}

Our sample consisted of 78 female participants comprising 26 female patients with BPD according to DSM-IV (APA, 2000), 22 patients with ADHD according to DSM-IV, and 30 female HC matched for age (18-43 years), education and intelligence (see Table 1). Patients were recruited at the Department of Psychosomatic Medicine and Psychotherapy and the Department of Psychiatry and Psychotherapy, Central Institute of Mental Health in Mannheim, Germany. Furthermore, participants were recruited via advertisements in newspapers, on websites, including disorder-specific internet forums, and via flyers for therapists. The study was approved by the local ethics committee and informed written consent was obtained from all participants.
Table I Patient's Characteristics

\begin{tabular}{|c|c|c|c|}
\hline Descriptive statistics & & Mean & SD \\
\hline \multirow[t]{4}{*}{ Age } & $\mathrm{HC}, \mathrm{N}=30$ & 27.53 & 6.60 \\
\hline & $\mathrm{BPD}, N=26$ & 27.54 & 6.53 \\
\hline & ADHD, $N=22$ & 30.05 & 6.74 \\
\hline & Total, $N=78$ & 28.24 & 6.63 \\
\hline \multirow[t]{3}{*}{ BSL-23 total } & $\mathrm{HC}$ & 2.60 & 4.11 \\
\hline & BPD & $45.54^{*, \#}$ & 21.39 \\
\hline & ADHD & $18.23^{*}, \S$ & 13.04 \\
\hline \multirow[t]{3}{*}{ ADHD-RS total } & $\mathrm{HC}$ & 6.53 & 5.45 \\
\hline & BPD & $18.77^{*}, \#$ & 8.28 \\
\hline & ADHD & $35.09 * \S$ & 7.46 \\
\hline \multirow[t]{3}{*}{$\mathrm{BDI}$} & $\mathrm{HC}$ & 2.24 & 3.29 \\
\hline & BPD & $30.73 * \#$ & 12.01 \\
\hline & $\mathrm{ADHD}$ & $\mid 6.41 *, \S$ & 12.30 \\
\hline \multirow[t]{3}{*}{ STAl } & $\mathrm{HC}$ & 31.97 & 7.67 \\
\hline & BPD & $61.81 *, \#$ & 10.83 \\
\hline & $A D H D$ & $53.96 * \S$ & 10.42 \\
\hline \multirow[t]{3}{*}{ CTQ } & $\mathrm{HC}$ & 30.07 & 5.08 \\
\hline & BPD & $72.50 \%, \#$ & 19.88 \\
\hline & $\mathrm{ADHD}$ & $45.64 \%, \S$ & 17.23 \\
\hline \multirow[t]{3}{*}{ DES } & $\mathrm{HC}$ & 0.25 & 0.18 \\
\hline & BPD & $2.68^{*, \#}$ & 1.51 \\
\hline & ADHD & $1.15 *, \S$ & 0.98 \\
\hline \multirow[t]{3}{*}{ CAARS total } & $\mathrm{HC}$ & 31.10 & 17.59 \\
\hline & BPD & $83.19 \%, \#$ & 29.38 \\
\hline & $\mathrm{ADHD}$ & $125.77^{*}, \S$ & 23.20 \\
\hline \multirow[t]{3}{*}{ BIS-1 I total } & $\mathrm{HC}$ & 53.40 & 7.43 \\
\hline & BPD & $63.69 \%, \#$ & 10.37 \\
\hline & ADHD & $83.86^{*, \S}$ & 8.13 \\
\hline \multirow[t]{3}{*}{ STAXI trait total } & $\mathrm{HC}$ & 16.23 & 3.53 \\
\hline & BPD & $28.12 *$ & 7.82 \\
\hline & $\mathrm{ADHD}$ & $25.59 *$ & 7.01 \\
\hline \multirow[t]{3}{*}{ BGLHA total } & $\mathrm{HC}$ & 1.23 & 1.94 \\
\hline & BPD & $9.50 *$ & 7.14 \\
\hline & $\mathrm{ADHD}$ & $8.32 *$ & 4.67 \\
\hline \multirow[t]{3}{*}{ GABA (i.u.) } & $\mathrm{HC}$ & 1.70 & 0.27 \\
\hline & BPD & 1.65 & 0.30 \\
\hline & ADHD & $1.50 *$ & 0.27 \\
\hline \multirow[t]{3}{*}{$\mathrm{Glu} / \mathrm{tCr}$} & $\mathrm{HC}$ & 1.07 & 0.08 \\
\hline & BPD & 1.07 & 0.09 \\
\hline & $\mathrm{ADHD}$ & 1.06 & 0.07 \\
\hline \multirow[t]{3}{*}{ GM/BM glutamate voxel } & $\mathrm{HC}$ & 0.82 & 0.03 \\
\hline & BPD & 0.84 & 0.06 \\
\hline & $\mathrm{ADHD}$ & 0.81 & 0.04 \\
\hline \multirow[t]{3}{*}{ GM/BM GABA voxel } & $\mathrm{HC}$ & 0.60 & 0.04 \\
\hline & BPD & 0.60 & 0.04 \\
\hline & ADHD & 0.58 & 0.04 \\
\hline
\end{tabular}

Numbers in bold and italic are significantly different from one or both other groups; the respective groups are marked by the following symbols.

*significantly different from $\mathrm{HC}$.

\# significantly different from ADHD.

significantly different from BPD.

\section{Diagnostic Assessments}

All participants underwent diagnostic assessments including the Structured Clinical Interview for DSM-IV Axis-I disorders (SCID-I (First et al, 1997)) and the Borderline Section of the International Personality Disorder Examination (IPDE (Loranger, 1999)). In addition, the Standard Progressive Matrices Test (Raven et al, 2003) and a German 
vocabulary intelligence test (Mehrfach-Wortschatz-Intelligenz-Test, Version B (Lehrl, 2005) were completed by all participants to estimate their intelligence. Inclusion criteria for the BPD group were at least five DSM-IV criteria for BPD (APA, 2000). For exclusion of ADHD diagnosis in BPD patients, three different measurements were applied: (1) the short version of the Wender Utah Rating Scale (WURS-k (Retz-Junginger et al, 2003)) to assess childhood ADHD symptoms; (2) the Connor Adult ADHD Rating Scale (Conners et al, 2002) was used, based on the DSM-IV criteria for ADHD (APA, 2000); (3) the Wender-Reimherr Adult Attention Deficit Disorder Scale (Rösler et al, 2008), which is a clinical interview conceptualized for adult ADHD. For the ADHD group, the same measurements were applied and BPD diagnosis was excluded via the IPDE. Substance use was assessed with the SCID-I (First et al, 1997). Furthermore, a urine drug screening was performed on the day of the MR investigation. No physical examinations were performed on the participants in the study. Medical and neurological conditions were gathered before participation in a detailed medical anamnesis. Serious physical and neurological diseases were exclusion criteria in this study. First-degree relatives of patients and controls were not necessarily free of psychiatric disorders.

Further clinical variables were assessed by self-reported measures concerning borderline symptom severity (Borderline Symptom List-23, BSL-23 (Bohus et al, 2007)), childhood trauma history (Childhood Trauma Questionnaire, CTQ, (Bernstein et al, 2003)), trait dissociation (Dissociative Experience Scale, DES (Bernstein and Putnam, 1986)), the State-Trait Anxiety Inventory, STAI (Spielberger et al, 1983), and depression (Bernstein and Putnam, 1986)) Beck Depression Inventory II (Beck et al, 1995).

All measurements and interviews were conducted by welltrained clinical psychologists and psychiatrists. Exclusion criteria for all participants were psychotropic medication within 2 weeks prior to the study, significant somatic disorders, pregnancy, and mental deficiency or developmental disorders. Patients were not generally free of medication. Some patients gradually reduced intake of their psychotropic medication (in consultation with their attending physician) and stopped intake 2 weeks before the study took place. Other patients were recruited while consulting a physician to start medication and were investigated before they started with pharmacotherapy. Lifetime history of any co-occurring psychiatric disorder was an exclusion criterion for HC. BPD and ADHD patients were not included if they had a lifetime history of bipolar affective disorder, psychotic disorder, current suicidal crisis, or substance abuse within the last 2 months.

\section{Assessment of Impulsivity and Aggression}

For impulsivity and aggression, the following self-rating scales were applied: the Barratt Impulsiveness Scale (BIS-11) (Preuss et al, 2008), the State-Trait Anger Expression Inventory (STAXI) (Schwenkmezger and Hodapp, 1991), and the Brown Goodwin Lifetime History of Aggression (BGLHA) (Brown et al, 1979). The BIS-11 consists of 30 items, which are answered on a four-point Likert scale $(1=$ 'rarely/never' to $4=$ 'always') and can be divided into the subscales Motor Impulsiveness, Non-Planning
Impulsiveness, and Attentional Impulsiveness. The BGLHA assesses different types of aggressive and antisocial behavior (ie, instances of fighting, temper tantrums, antisocial behavior involving the police), where each item is rated on a scale from $0-4$, indicating the frequency of these events ranging from 'never' to 'more than four times'. The trait version of the STAXI consists of 10 items assessing the disposition to experience anger. All items are rated on a fourpoint Likert scale ranging from 1 (almost never) to 4 (almost always). The BGLHA is a measurement of past overt aggressive behavior in contrast to the STAXI, which measures the tendency to feel anger (which may or may not provoke aggressive behavior). As anxiety and anger are both high arousal, negatively valenced emotions, a strong relationship can be expected.

\section{MR Spectroscopy}

In vivo, single voxel $1 \mathrm{H}$ MRS was performed at a $3.0 \mathrm{~T}$ wholebody MR scanner with a 32 channel receive-only head coil (Siemens Magnetom TIM Trio). Two MRS voxels were acquired and both were placed on the ACC based on an isotropic $1 \mathrm{~mm}^{3}$ MPRAGE data set with reconstructed coronal and transverse planes aligned with the shape of the corpus callosum (see Figure 1). With a MEGA-PRESS sequence for GABA editing, a $40 \times 30 \times 20 \mathrm{~mm}^{3}$ voxel was acquired ( $\mathrm{TE}=68 \mathrm{~ms}, \mathrm{TR}=3 \mathrm{~s}, \mathrm{NEX}=96 \mathrm{on}, 96 \mathrm{off}$ ) (Figure 1). The editing pulse (Gauss shape, $20.36 \mathrm{~ms}$ length, bandwidth (FWHM): $44 \mathrm{~Hz}$ ) in the MEGA-PRESS sequence was switched between 1.9 and $1.5 \mathrm{ppm}$ (second editing frequency $1.5 \mathrm{ppm}$ ) alternating every excitation. This editing scheme diminishes contamination by nearby MM resonances (Aufhaus et al, 2013; Henry et al, 2001: Aufhaus, 2013 \#13421)

The glutamate signal was analyzed from a smaller and thus more exactly localized voxel of $15 \times 30 \times 12 \mathrm{~mm}^{3}$ acquired with a PRESS sequence in the ACC $(\mathrm{TE}=80 \mathrm{~ms}, \mathrm{TR}=3 \mathrm{~s}$, $\mathrm{NEX}=96$ (Schubert et al, 2004)) owing to the higher concentration and thus better Signal to Noise Ratio for glutamate compared with GABA.

For quantification of the (in vivo) spectra, the GABA signals were analyzed using the jMRUI-software (Stefan et al, 2009). The MEGA-PRESS sequence includes an editing pulse mirrored at $1.7 \mathrm{ppm}$ (1.9 ppm and $1.5 \mathrm{ppm})$. This editing scheme does not only suppress the MM signals but additionally results in a different spectral pattern for GABA compared with the pulse schemes without macromolecule suppression. The jMRUI procedure included zerofilling to 2048 points, slight apodization ( $4 \mathrm{~Hz}$, Lorentzian shape), and HLSVD filtering of the residual water peak. Three peaks with Lorentzian shape were used to fit GABA.

For the other metabolites, LCModel (Provencher, 1993) was used with a simulated basis data set (based on Gamma routines) containing the following metabolites: alanine, aspartate, creatine and phosphocreatine (tCr), GABA, glucose, glutamine, glutamate, glycerol-phosphoryl-choline, phosphoryl-choline, myo-Inositol, lactate, $\mathrm{N}$-acetylaspartate, $N$-acetylaspartylglutamate, scyllo-Inositol, and taurine. In addition, signals of macromolecules and lipids were directly simulated by LCModel. Glutamate was evaluated as a ratio to total creatine $(\mathrm{Glu} / \mathrm{tCr})$. In the edited GABA spectra, the $\mathrm{tCr}$ signal is edited out. As we have previously established a quantitation method for GABA (Aufhaus et al, 2013) based 


\section{a}
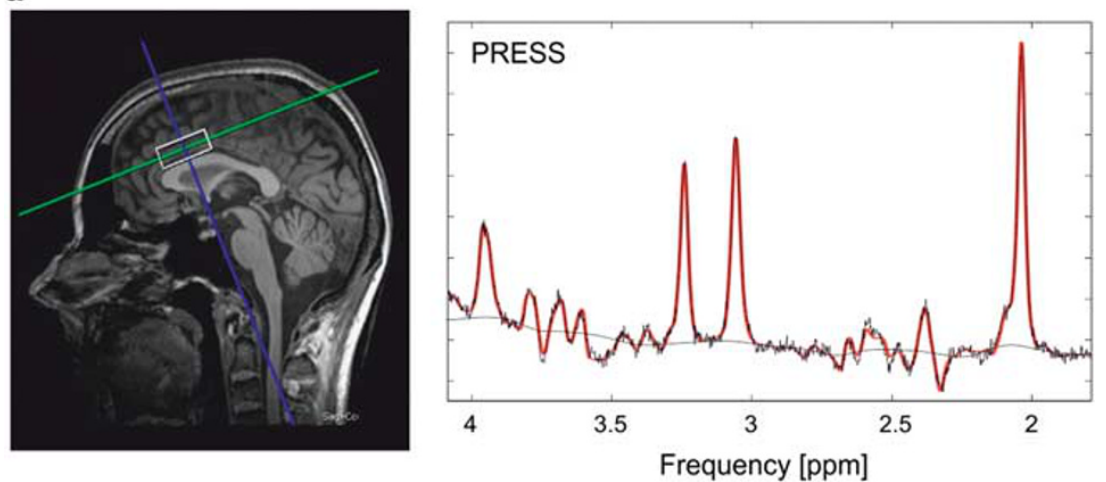

b
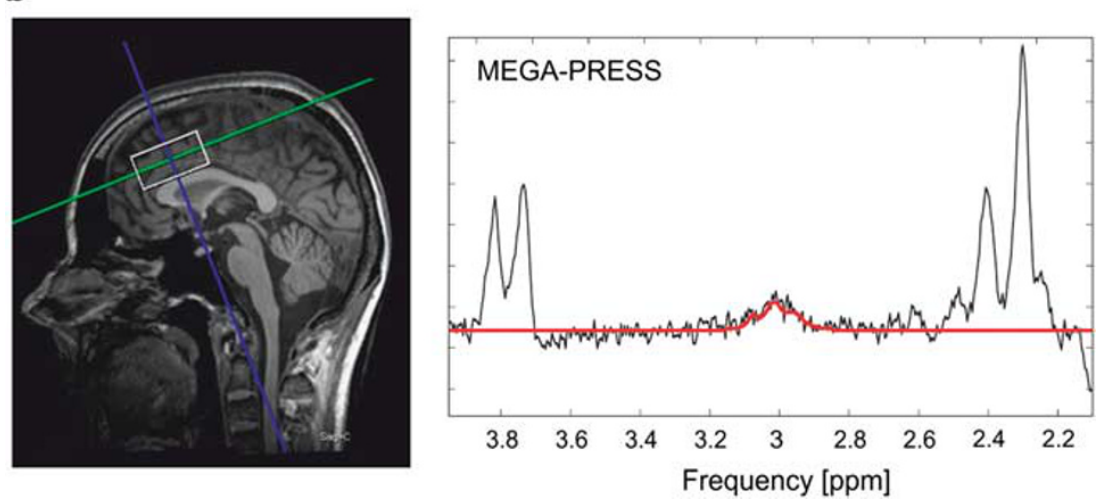

Figure I Localizer images with PRESS boxes and exemplary spectra for (a) Glu/tCr detection and (b) GABA detection.

on phantom measurements including correction for the voxel's tissue compartmentation (Weber-Fahr et al, 2002), quantitative values for GABA levels are reported. All spectra were of good quality and spectral fits had Cramer rao Lower Bounds below 20 for glutamate and GABA (no subject was excluded).

\section{Statistical Analyses}

Statistical analyses were performed using SPSS 21.0 for Microsoft Windows (SPSS). For analyses of group differences in demographic and psychometric variables, a multivariate general linear model analysis was applied. Group differences in GABA and in Glu/tCr were investigated with univariate general linear model analyses. Correlation analyses of GABA and Glu/tCr with psychometrics of impulsivity and aggression were performed as partial correlation for all subjects, controlling for disease state coded as two binary variables. Further correlations were calculated for the individual groups' GABA and Glu/tCr levels with impulsivity additionally controlling for aggression and for anxiety and with aggression additionally controlling for impulsivity and for anxiety. The threshold for statistical significance was set at $P<0.05$.

The ADHD diagnostic score CAARS consists of factorderived subscales for inattention/memory problems, hyperactivity/restlessness, impulsivity/emotional liability, and problems with self-concept. The behavioral measure 'hyperactivity' is not explicitly covered by the BIS-11, STAXI, and BGLHA scores. Thus, we additionally determined exploratively whether the CAARS subscores and especially the hyperactivity subscore show significant relations to the observed $\mathrm{Glu} / \mathrm{tCr}$ and/or GABA levels. Further, we tested whether the hyperactivity subscore significantly affects the correlations of impulsivity and aggression with $\mathrm{Glu} / \mathrm{tCr}$ and GABA.

We additionally performed the correlation analyses group wise. Here, we tested for the difference between two independent correlation coefficients using Fisher's $z$-transformation (Preacher, 2002).

\section{RESULTS}

\section{Demographic and Clinical Characteristics}

Patient's characteristics are summarized in Table 1. Both patient groups were not free of further comorbid disorders. None of the subjects had been included in our previous study (Hoerst et al, 2010). The lifetime and current prevalences of comorbidities in both patient groups are listed in Table 2. The three groups (BPD, ADHD, HC) did not differ in age, intelligence, and education. Disorder-specific symptom ratings were all significantly higher in the patient groups than in the HC group. As expected, BPD patients scored higher in the BSL-23 score than the ADHD group and HC, whereas ADHD patients scored higher in all ADHD measures (WURS-k, CAARS) than BPD patients and HC. The CAARS total score and all its subscores significantly differentiated the ADHD group from the BPD group, but were also significantly higher in BPD than HC. Descriptively, the subscale inattention had the greatest relative difference between BPD $(12.0 \pm 6.8)$ and ADHD $(23.3 \pm 6.9)$ followed by the subscale hyperactivity $(14.7 \pm 7.3$ in $\mathrm{BPD}$ vs $22.0 \pm 6.1$ in $\mathrm{ADHD})$. 
Table 2 Lifetime and Current Prevalences of Comorbidities in both Patient Groups

\begin{tabular}{lccccc}
\hline & \multicolumn{2}{c}{ Lifetime } & & \multicolumn{2}{c}{ Current } \\
\cline { 2 - 3 } \cline { 5 - 6 } Comorbidities & $\begin{array}{c}\text { BPD } \\
(\mathbf{N}=\mathbf{2 6})\end{array}$ & $\begin{array}{c}\text { ADHD } \\
(\mathbf{N}=\mathbf{2 2})\end{array}$ & & $\begin{array}{c}\text { BPD } \\
(\mathbf{N}=\mathbf{2 6})\end{array}$ & $\begin{array}{c}\text { ADHD } \\
(\mathbf{N}=\mathbf{2 2})\end{array}$ \\
\hline MDD & 20 & 7 & & 2 & 0 \\
Anxiety disorder & 17 & 5 & & 11 & 0 \\
Substance abuse & 11 & 5 & & 3 & 5 \\
Eating disorder & 16 & 4 & & 7 & 3 \\
PTSD & 13 & 1 & & 13 & 1 \\
OCD & 13 & 0 & & 2 & 0 \\
Individual range & $0-5$ & $0-4$ & & $0-4$ & $0-2$ \\
Mean \pm SD & $3.2 \pm 1.4$ & $1.1 \pm 1.2$ & & $1.6 \pm 1.1$ & $0.4 \pm 0.6$ \\
\hline
\end{tabular}

\section{Impulsivity and Aggression}

Both patient groups displayed elevated self-reported trait impulsivity (BIS total), anger (STAXI), aggression (BGLHA), depression scores (BDI), childhood trauma history (CTQ), and trait dissociation (DES) compared with HCs. As compared with BPD patients, ADHD patients reported higher impulsivity in all BIS-11 facets (non-planning, motor, and attentional impulsivity). No significant differences between patient groups were found in anger (STAXI) and aggression (BGLHA) scores (Table 1).

The aggression scores BGLHA and STAXI for the whole group (controlling for BPD and ADHD) are highly correlated $(r=0.67 ; P<0.001)$, but only STAXI is significantly correlated with the anxiety score STAI. The impulsivity score BIS-11 total also yields a significant correlation with the STAI score $(r=0.25 ; P<0.03)$, and shows a trend but no significant correlations with neither BGLHA $(r=0.17 ; P=0.13)$ nor STAXI $(r=0.21 ; P=0.06)$. The BDI depression score yields significant correlations with STAXI and STAI $(r>0.35, P<0.003)$ but not with BIS-11 and BGLHA $(r<0.12, P>0.3)$.

\section{MR Spectroscopy}

Neither GABA nor Glu/tCr was associated with either age $(r<-0.17 ; P>0.14)$ or the voxel's gray matter content expressed as the gray matter/brain matter (GM/BM) ratio $(r<0.07 ; P>0.5)$, whereas the $\mathrm{GM} / \mathrm{BM}$ ratio significantly decreased with age ( $r=-0.31 ; P=0.006)$. Thus, age and GM/ $\mathrm{BM}$ were not used as covariates for the further group comparisons and correlations for GABA and Glu/tCr. In a general linear model, a significant group difference among $\mathrm{HC}, \mathrm{BPD}$, and ADHD was observed for GABA. Tukey's post hoc test yielded that ADHD patients exhibit significantly lower GABA levels than controls (Table 1). The Glu/tCr ratio was not significantly different between groups (Table 1).

\section{GABA, Glutamate, and Impulsivity}

A significant positive partial correlation was observed between the BIS-11 total score and $\mathrm{Glu} / \mathrm{tCr}$, controlling for diagnosis with two binary variables. As expected, a
Table 3 GABA and Glu/tCr Correlations with Behavioral Test Scores

\begin{tabular}{|c|c|c|c|c|}
\hline \multirow{2}{*}{$\begin{array}{l}\text { Partial correlation controlled for } \\
\text { ADHD and BPD, } d f=74\end{array}$} & \multicolumn{2}{|c|}{ GABA (mM) } & \multicolumn{2}{|c|}{ Glu/tCr } \\
\hline & $R$ & $P$-value & $r$ & $P$-value \\
\hline BIS-I I total & -0.25 & 0.03 & 0.32 & 0.005 \\
\hline Controlled for aggression & -0.25 & 0.08 & 0.30 & 0.01 \\
\hline Controlled for anxiety & -0.18 & 0.12 & 0.28 & 0.01 \\
\hline BGLHA total & -0.27 & 0.02 & 0.10 & 0.39 \\
\hline Controlled for impulsivity & -0.24 & 0.04 & 0.10 & 0.41 \\
\hline Controlled for anxiety & -0.23 & 0.04 & 0.12 & 0.32 \\
\hline \multicolumn{5}{|l|}{ Explorative analyses } \\
\hline CAARS total & -0.33 & 0.004 & $0.4 I$ & $<0.001$ \\
\hline CAARS inattention & -0.29 & 0.01 & 0.38 & 0.001 \\
\hline CAARS hyperactivity & -0.19 & 0.1 & 0.19 & 0.1 \\
\hline BSL-23 total & -0.25 & 0.03 & 0.12 & 0.3 \\
\hline
\end{tabular}

Numbers in bold and italic indicate significant correlation coefficients and respective $p$-values.

significant negative partial correlation between BIS-11 total score and GABA (Table 3 \& Figures 2a-d) was found. Although the inclusion of the anxiety and aggression scores as potential confounders in the partial correlation with Glu/ tCr did not affect the significance, the negative correlation with GABA was reduced to a trend level (Table 3).

\section{GABA, Glutamate, and Aggression}

A significant negative partial correlation controlling for diagnosis with two binary variables between the BGLHA aggression score and GABA, but no positive correlation with Glu/tCr was found. Neither controlling for impulsivity, nor BDI nor STAI scores in a partial correlation explained the negative correlation of BGLHA with GABA significant (Table 3).

\section{Explorative Analysis of the BSL Score and CAARS Scores in Relation to GABA and Glutamate Levels}

The BSL score assessed in our study is significantly correlated with the aggression score $(r=0.29, P=0.009)$ but not the BIS-11 impulsivity score $(P=0.25)$. Accordingly, we observe a significant negative correlation of the BSL score with GABA $(r=-0.25, P=0.03)$. The CAARS total scores assessed in our study are highly correlated with both the BIS-11 total scores $(r=0.59, P<0.001)$ and the aggression scores BGLHA and STAXI $(r>0.35, P<0.001)$. It further yields significant, equally directed correlations with $\mathrm{Glu} / \mathrm{tCr}$ $(r=0.40, P<0.001)$ and GABA $(r=-0.27, P=0.02)$ as observed for the impulsivity and aggressions scores. Neither Glu/tCr $(r=0.19, P=0.09)$ nor GABA $(r=-0.19, P=0.10)$ yielded a significant association with the subscore hyperactivity. The partial correlations with the hyperactivity score used as a control variable still yielded significant results for impulsivity and $\mathrm{Glu} / \mathrm{tCr}(r=-0.28, P=0.01)$ as well as for aggression and GABA $(r=-0.23, P=0.05)$. 

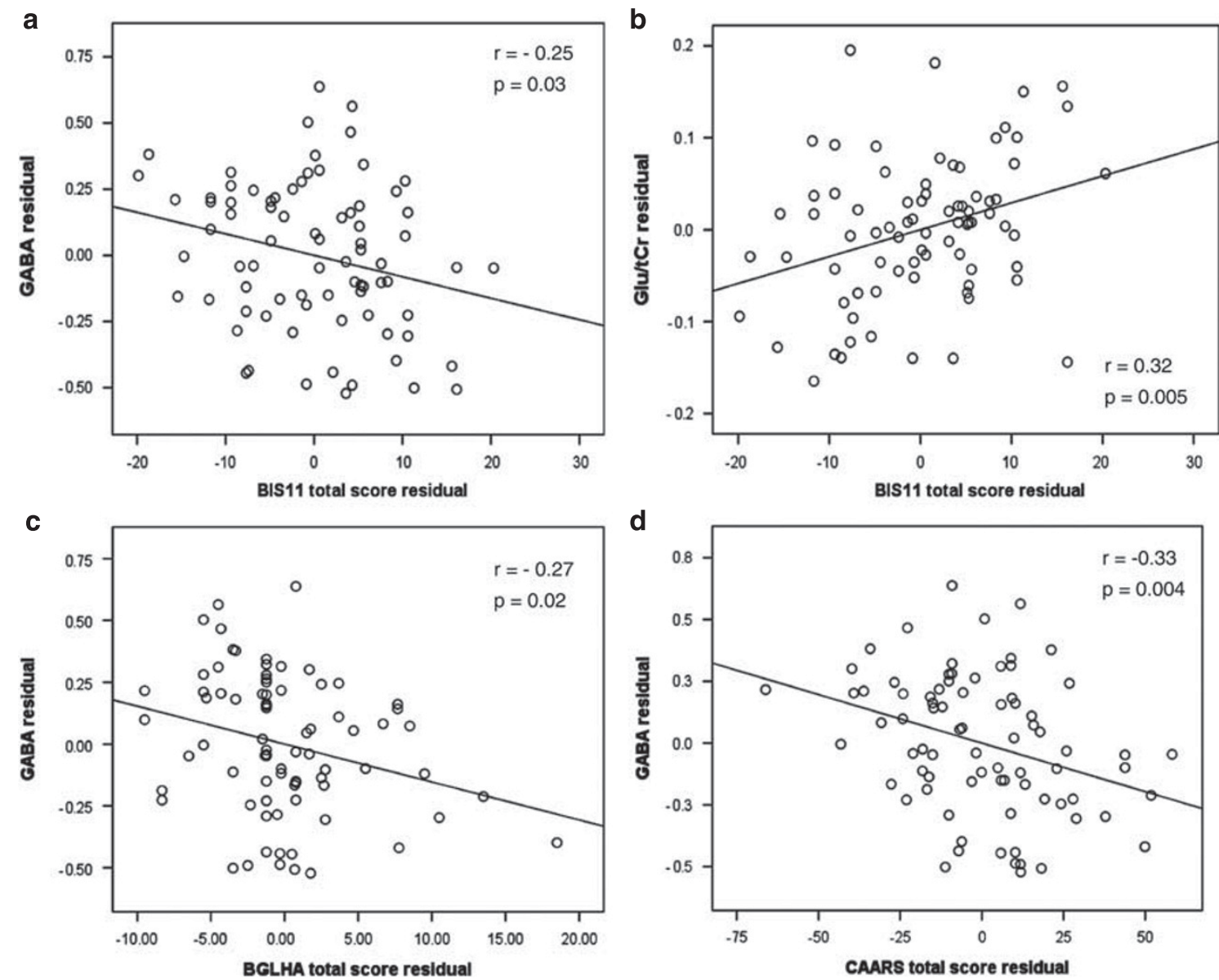

Figure 2 Scatter plot representations of the partial correlations (controlled for BPD and ADHD thus all variables expressed as residuals) of (a) GABA and the BIS-I I total impulsivity score, (b) Glu/tCr and the BIS-I I total impulsivity score; (c) GABA and the BGLHA score, and (d) GABA and the CAARS inattention score.

\section{Group-Wise Correlation Analyses}

Group-wise correlation analyses yielded for the BPD, a significant positive correlation, of Glu/tCr with BIS-11 total (BPD: $r=0.46, P=0.02$ ) and a negative correlation for the BPD and the HC group for the aggression score BGLHA with GABA $(r<-0.41, P<0.025)$ but neither correlation was significant for the ADHD group $(P>0.7)$.

The explorative correlation analyses with the CAARS subscores yielded a strong correlation for GABA with CAARS inattention for the ADHD group $(r=-0.57$, $P=0.006)$ but not the BPD group $(r=-0.07, P=0.7)$. For CAARS inattention but none of the other group-wise evaluations, the correlation coefficients for the two groups were significantly different in a fisher $z$-transformation test $(Z$-score $=1.84, P=0.03)$.

\section{DISCUSSION}

This study provides evidence that in the ACC levels of Glu/ $\mathrm{tCr}$ and GABA are related to self-reported impulsivity. We observed a positive correlation of BIS-11 scores with $\mathrm{Glu} / \mathrm{tCr}$ and an inverse correlation of the BIS-11 score with GABA levels. The latter is reduced to trend level if the correlation is controlled for aggression and/or anxiety. For aggression, significant correlations were only found for GABA, which is negatively correlated with the BGLHA aggression measure.

Regarding impulsivity, anger, and aggression, we found higher scores in BPD and ADHD patients compared with HCs, which are in line with our previous studies in independent patient cohorts (Cackowski et al, 2014; Krause-Utz et al, 2013). Further, BPD and ADHD patients differed in every aspect of impulsivity, but not in anger and aggression. ADHD patients reported generally elevated impulsivity (BIS-11 total score), stronger tendencies to act without thinking (motor impulsivity), more deficits in planning and future-orientation (non-planning impulsivity), and more problems maintaining attention on a task/being more distractible (attentional impulsivity).

On the neurochemical level, we found evidence for disorderspecific GABA associations: the group of ADHD patients, but not BPD patients, exhibited lower GABA levels in the ACC in comparison with the $\mathrm{HC}$ group. In contrast to two previous studies in ADHD where a reduced Glu/tCr level in ADHD was found in a prefrontal voxel (Dramsdahl et al, 2011) and the posterior cingulate cortex (Arcos-Burgos et al, 2012), we did not find group differences for $\mathrm{Glu} / \mathrm{tCr}$ in the ACC. As hypothesized, our previous observations of a significant positive correlation of glutamate with self-reported impulsivity in the ACC were substantiated. Furthermore, a trend for an 
opposite association of impulsivity scores with GABA was observed. For the BGLHA aggression score, a negative relation was found with GABA levels. Analyzing each group separately, significant associations of $\mathrm{Glu} / \mathrm{tCr}$ with impulsivity were detected in BPD patients, and of GABA with aggression in $\mathrm{BPD}$ and $\mathrm{HC}$, but neither correlation was significant for the ADHD patient group. Whether this was a problem of insufficient group size and thus power or truly related to the distinguished disorders needs to be explored in future studies.

Finally, especially in the ADHD group, low ACC GABA was strongly associated with high inattention scores, whereas hyperactivity did neither correlate with ACC GABA nor Glu/ tCr levels. Together with the significantly lower GABA level in the ADHD group compared with the HC group, which was also found in ADHD children in another brain region (Edden et al, 2012), this hints toward an important role of ACC GABA in attention regulation.

Our findings of positive correlations of the BIS-11 total impulsivity score with $\mathrm{Glu} / \mathrm{tCr}$ and a trend for a negative correlation with GABA adds further support for the involvement of glutamatergic and GABAergic mechanisms in the expression of impulsivity (Hayes et al, 2014; Jupp et al, 2013; Murphy et al, 2012 ). In a group-wise correlation analyses, the Glu/tCr correlations hold for the BPD group. In the ADHD group, only a relation of GABA to the CAARS inattention subscale reached significance. One could speculate that the mechanisms for elevated impulsivity are distinct in BPD and ADHD patients. An interpretation of these disorder-specific associations still needs some caution given the small sample size of the ADHD group and the fact that all correlation coefficients with the exception of the CAARS inattention subscore were not found significantly different in a test using the Fisher's $z$-transformation. Furthermore, hyperactivity scores were neither associated with $\mathrm{Glu} / \mathrm{tCr}$ nor with GABA levels, neither in the total group nor in the subgroups. Recently, distinct striatal regions have been implicated as possible core regions for ADHD (Ikeda et al, 2013) and its relation to GABA in animal models (Caprioli et al, 2014). If distinct neurochemical mechanisms for impulsivity and aggression can be confirmed in future studies, these mechanisms may yield important implications for more specific pharmacological treatments.

A potential limitation of this study could be that the individual groups of $\operatorname{BPD}(n=26)$ and $\operatorname{ADHD}(n=22)$ patients may not have been large enough to find all existing disorder-specific associations with impulsivity, aggression, and inattention. Some effects, especially in the ADHD group, might have stayed undetected owing to power issues. Although we excluded ADHD as comorbidity for the BPD group and vice versa, other comorbidities might have diluted disorder-specific findings. Comorbidities were somewhat less frequent in the ADHD group. Nevertheless, ADHD, as recently described by Karalunas et al, 2014, is not a uniform disorder but can further be divided into three subtypes by a biologically informed temperament-based typology, thus impulsivity and aggression might not be equally expressed in these three subtypes, which we did not differentiate. Furthermore, our MRS findings are not yet linked to other imaging parameters such as default mode network connectivity or task-related functional activation. The use of the $\mathrm{Glu} / \mathrm{tCr}$ ratio assumes that there is no significant alteration of $\mathrm{tCr}$ in $\mathrm{BPD}$ and $\mathrm{ADHD}$. In our own study of BPD patients
(Hoerst et al, 2010) and in the study by Rusch et al, 2010a of BPD patients with comorbid ADHD, no ACC tCr changes have been observed. Another limitation is the lack of a control region for the MRS data that preclude statements regarding regional specificity of neurochemistry in the ACC in the behaviors measured. Future studies should combine the potential of various imaging methods to ultimately derive imaging markers for psychopathological traits such as impulsivity, aggression, and inattention, which are important for the understanding and treatment of a variety of psychiatric disorders including BPD and ADHD.

\section{FUNDING AND DISCLOSURE}

The authors declare no conflict of interest.

\section{ACKNOWLEDGMENTS}

The study was supported by a grant from the German Research Foundation (DFG) to GE and CS (EN 361/12-1 SCHM 1526/13-1). MB is a consultant for AOK insurance company; he receives grants by the German Research Foundation (DFG), The Ministry of Research, Germany (BMBF), CS revceives grants from the DFG and BMBF, ES is an advisor for Medice, Eli Lilly, Shire and gives lectures for Eli Lilly, Medice.

\section{REFERENCES}

APA (2000). Diagnostic and Statistical Manual of Mental Disorders, 4th edn, text revision (DSM-IV-TR). American Psychiatric Press: Washington, DC, USA.

Arcos-Burgos M, Londono AC, Pineda DA, Lopera F, Palacio JD, Arbelaez A et al (2012). Analysis of brain metabolism by proton magnetic resonance spectroscopy (1H-MRS) in attention-deficit/hyperactivity disorder suggests a generalized differential ontogenic pattern from controls. Atten Defic Hyperact Disord 4: 205-212.

Aufhaus E, Weber-Fahr W, Sack M, Tunc-Skarka N, Oberthuer G, Hoerst $M$ et al (2013). Absence of changes in GABA concentrations with age and gender in the human anterior cingulate cortex: a MEGA-PRESS study with symmetric editing pulse frequencies for macromolecule suppression. Magn Reson Med 69: 317-320.

Beck AT, Steer RA, Brown GK, Hautzinger M, Keller F, Kühner C (1995). Beck-Depressions-Inventar. Deutsche Version. Hogrefe Testzentrale: Göttingen, Germany.

Berkowitz L (1993). Aggression: its causes, consequences, and control. McGraw-Hill: New York, NY, USA.

Bernstein DP, Stein JA, Newcomb MD, Walker E, Pogge D, Ahluvalia $\mathrm{T}$ et al (2003). Development and validation of a brief screening version of the Childhood Trauma Questionnaire. Child Abuse Negl 27: 169-190.

Bernstein EM, Putnam FW (1986). Development, reliability, and validity of a dissociation scale. J Nerv Mental Dis 174: 727-735.

Bohus M, Limberger MF, Frank U, Chapman AL, Kuhler T, Stieglitz RD (2007). Psychometric properties of the Borderline Symptom List (BSL). Psychopathology 40: 126-132.

Boy F, Evans CJ, Edden RA, Lawrence AD, Singh KD, Husain M et al (2011). Dorsolateral prefrontal gamma-aminobutyric acid in men predicts individual differences in rash impulsivity. Biol Psychiatry 70: 866-872.

Brown GL, Goodwin FK, Ballenger JC, Goyer PF, Major LF (1979). Aggression in humans correlates with cerebrospinal fluid amine metabolites. Psychiatry Res 1: 131-139. 
Cackowski S, Reitz AC, Ende G, Kleindienst N, Bohus M, Schmahl C et al (2014). Impact of stress on different components of impulsivity in borderline personality disorder. Psychol Med 44: 3329-3340.

Caprioli D, Sawiak SJ, Merlo E, Theobald DE, Spoelder M, Jupp B et al (2014). Gamma aminobutyric acidergic and neuronal structural markers in the nucleus accumbens core underlie trait-like impulsive behavior. Biol Psychiatry 75: 115-123.

Comai S, Tau M, Gobbi G (2012a). The psychopharmacology of aggressive behavior: a translational approach: part 1: neurobiology. J Clin Psychopharmacol 32: 83-94.

Comai S, Tau M, Pavlovic Z, Gobbi G (2012b). The psychopharmacology of aggressive behavior: a translational approach: part 2: clinical studies using atypical antipsychotics, anticonvulsants, and lithium. J Clin Psychopharmacol 32: 237-260.

Conners CK, Erhardt D, Sparrow E (2002). Conners' Adult ADHD Rating Scales: (CAARS). MHS: London, UK.

Connor DF, Chartier KG, Preen EC, Kaplan RF (2010). Impulsive aggression in attention-deficit/hyperactivity disorder: symptom severity, co-morbidity, and attention-deficit/hyperactivity disorder subtype. J Child Adolesc Psychopharmacol 20: 119-126.

Davids E, Gastpar M (2005). Attention deficit hyperactivity disorder and borderline personality disorder. Prog Neuropsychopharmacol Biol Psychiatry 29: 865-877.

Dramsdahl M, Ersland L, Plessen KJ, Haavik J, Hugdahl K, Specht K (2011). Adults with attention-deficit/hyperactivity disorder - a brain magnetic resonance spectroscopy study. Front Psychiatry 2: 65.

Edden RA, Crocetti D, Zhu H, Gilbert DL, Mostofsky SH (2012). Reduced GABA concentration in attention-deficit/hyperactivity disorder. Arch Gen Psychiatry 69: 750-753.

First MB, Spitzer RL, Gibbon M, Williams JBW (1997). Structured Clinical Interview for DSM-IV Axis I Disorders - Clinical Version (SCID-CV). American Psychiatric Press: Washington, DC, USA.

Hayes DJ, Jupp B, Sawiak SJ, Merlo E, Caprioli D, Dalley JW (2014). Brain gamma-aminobutyric acid: a neglected role in impulsivity. Eur J Neurosci 39: 1921-1932.

Henry PG, Dautry C, Hantraye P, Bloch G (2001). Brain GABA editing without macromolecule contamination. Magn Reson Med 45: $517-520$

Hoerst M, Weber-Fahr W, Tunc-Skarka N, Ruf M, Bohus M, Schmahl C et al (2010). Correlation of glutamate levels in the anterior cingulate cortex with self-reported impulsivity in patients with borderline personality disorder and healthy controls. Arch Gen Psychiatry 67: 346-354.

Ikeda H, Koshikawa N, Cools AR (2013). Accumbal core: essential link in feed-forward spiraling striato-nigro-striatal in series connected loop. Neuroscience 252: 60-67.

Jupp B, Caprioli D, Saigal N, Reverte I, Shrestha S, Cumming P et al (2013). Dopaminergic and GABA-ergic markers of impulsivity in rats: evidence for anatomical localisation in ventral striatum and prefrontal cortex. Eur J Neurosci 37: 1519-1528.

Karalunas SL, Fair D, Musser ED, Aykes K, Iyer SP, Nigg JT (2014). Subtyping attention-deficit/hyperactivity disorder using temperament dimensions: toward biologically based nosologic criteria. JAMA Psychiatry 71: 1015-1024.

Krause-Utz A, Sobanski E, Alm B, Valerius G, Kleindienst N, Bohus $M$ et al (2013). Impulsivity in relation to stress in patients with borderline personality disorder with and without co-occurring attention-deficit/hyperactivity disorder: an exploratory study. J Nerv Ment Dis 201: 116-123.

Lampe K, Konrad K, Kroener S, Fast K, Kunert HJ, Herpertz SC (2007). Neuropsychological and behavioural disinhibition in adult ADHD compared to borderline personality disorder. Psychol Med 37: 1717-1729.

Latalova K, Prasko J (2010). Aggression in borderline personality disorder. Psychiatric Q 81: 239-251.
Lehrl S (2005). Mehrfachwahl-Wortschatz-Intelligenztest MWTB5th edn.Spitta Verlag: Balinge, Germany.

Loranger AW (1999). International Personality Disorder Examination (IPDE): DSMIV and ICD-10 Modules. Psychological Assessment Resources: Odessa, FL, USA.

Mancke F, Herpertz SC, Bertsch K. Aggression in borderline personality disorder - a multidimensional model. Personality Disorders. (in press).

Murphy ER, Fernando AB, Urcelay GP, Robinson ES, Mar AC, Theobald DE et al (2012). Impulsive behaviour induced by both NMDA receptor antagonism and GABAA receptor activation in rat ventromedial prefrontal cortex. Psychopharmacology 219: 401-410.

Philipsen A, Limberger MF, Lieb K, Feige B, Kleindienst N, Ebner-Priemer U et al (2008). Attention-deficit hyperactivity disorder as a potentially aggravating factor in borderline personality disorder. Br J Psychiatry 192: 118-123.

Preacher KJ (2002). Calculation for the test of the difference between two independent correlation coefficients http://quantpsy. org: Nashville.

Preuss UW, Rujescu D, Giegling I, Watzke S, Koller G, Zetzsche T et al (2008). [Psychometric evaluation of the German version of the Barratt Impulsiveness Scale]. Der Nervenarzt 79: 305-319.

Provencher SW (1993). Estimation of metabolite concentrations from localized in vivo proton NMR spectra. Magn Reson Med 30: 672-679.

Raven J, Raven JC, Court JH (2003). Raven's Progressive Matrices und Vocabulary Scales. Pearson Assessment: Frankfurt, Germany.

Retz-Junginger P, Retz W, Blocher D, Stieglitz RD, Georg T, Supprian $T$ et al (2003). [Reliability and validity of the WenderUtah-Rating-Scale short form. Retrospective assessment of symptoms for attention deficit/hyperactivity disorder]. Der Nervenarzt 74: 987-993.

Rösler M, Retz W, Retz-Junginger P, Stieglitz RD, Kessler H, Reimherr F et al (2008). Attention deficit hyperactivity disorder in adults. Benchmarking diagnosis using the Wender-Reimherr adult rating scale. Nervenarzt 79: 320-327. doi: 10.1007/s00115-007-2375-0

Rusch N, Boeker M, Buchert M, Glauche V, Bohrmann C, Ebert D et al (2010a). Neurochemical alterations in women with borderline personality disorder and comorbid attention-deficit hyperactivity disorder. World J Biol Psychiatry 11: 372-381.

Rusch N, Bracht T, Kreher BW, Schnell S, Glauche V, Il'yasov KA et al (2010b). Reduced interhemispheric structural connectivity between anterior cingulate cortices in borderline personality disorder. Psychiatry Res 181: 151-154.

Sacchetti GM, Lefler EK (2014). ADHD symptomology and social functioning in college students. J Atten Disord. 17 November 2014. pii: 1087054714557355 . (Epub ahead of print).

Schubert F, Gallinat J, Seifert F, Rinneberg H (2004). Glutamate concentrations in human brain using single voxel proton magnetic resonance spectroscopy at 3 Tesla. Neuroimage 21: $1762-1771$.

Schwenkmezger P, Hodapp V (1991). [A questionnaire for assessing anger and expression of anger]. Z Klinische Psychol Psychopathol Psychother 39: 63-68.

Sebastian A, Jung P, Krause-Utz A, Lieb K, Schmahl C, Tuscher O (2014). Frontal dysfunctions of impulse control - a systematic review in borderline personality disorder and attention-deficit/ hyperactivity disorder. Front Hum Neurosci 8: 698.

Sebastian A, Pohl MF, Kloppel S, Feige B, Lange T, Stahl C et al (2013). Disentangling common and specific neural subprocesses of response inhibition. Neuroimage 64: 601-615.

Silveri MM, Sneider JT, Crowley DJ, Covell MJ, Acharya D, Rosso IM et al (2013). Frontal lobe gamma-aminobutyric acid levels during adolescence: associations with impulsivity and response inhibition. Biol Psychiatry 74: 296-304. 
Spielberger CD, Gorsuch RL, Lushene R, Vagg PR, Jacobs GA (1983). Manual for the State-Trait Anxiety Inventory Consulting Psychologists Press. Palo Alto: CA, USA.

Stefan D, Di Cesare F, Andrasescu A, Popa E, Lazariev A, Vescovo E et al (2009). Quantitation of magnetic resonance spectroscopy signals: the jMRUI software package. Meas Science Technol 20: 104035-104044.
Weber-Fahr W, Ende G, Braus DF, Bachert P, Soher BJ, Henn FA et al (2002). A fully automated method for tissue segmentation and CSF-correction of proton MRSI metabolites corroborates abnormal hippocampal NAA in schizophrenia. Neuroimage 16: 49-60.

Wender PH, Wolf LE, Wasserstein J (2001). Adults with ADHD. An overview. Ann N Y Acad Sci 931: 1-16. 